Apuntes sobre el concepto postcolonialidad: Semejanzas y diferencias en su concepción y uso entre los intelectuales indios y latinoamericanistas Javier Pinedo

Pp. 189 a 216

\title{
APUNTES SOBRE EL CONCEPTO POSTCOLONIALIDAD: SEMEJANZAS Y DIFERENCIAS EN SU CONCEPCIÓN Y USO ENTRE LOS INTELECTUALES INDIOS Y LATINAMERICANISTAS
}

\author{
Notes on the postcolonial concept: Similarities and differences in their concept and use \\ among Indian and Latin American intellectuals
}

Javier Pinedo*

\section{RESUMEN}

El artículo expone el significado y uso del concepto postcolonialidad por parte de los intelectuales de la India y su adaptación en América Latina, especialmente por el Grupo Latinoamericano de Estudios Subalternos (1995), para establecer semejanzas y diferencias entre el modo cómo unos y otros utilizan este concepto al analizar sus respectivas épocas coloniales y su presente. Postulamos que los intelectuales surasiáticos inician su reflexión desde la realidad social y política para intentar resolver la situación del subalterno de su país inmediatamente después de la Independencia en 1947, definidos como seres marginales poseedores de una cultura ancestral a la que nadie sino ellos mismos tienen acceso, y al mismo tiempo privados de todos los derechos de la modernidad ilustrada. Los intelectuales latinoamericanos, en cambio, con excepción de los trabajos de Florencia Mallon, José Rabasa y algunos otros, poseen una visión más académica del subalterno, y actúan como una toma de posición al interior de la Historia intelectual, distanciándose de la postcolonialidad original para centrase en una defensa epistemológica de América Latina frente a la modernidad y el sistema mundo.

Palabras clave: América Latina, India, postcolonialidad, sujeto subalterno, pensamiento periférico.

\footnotetext{
* Instituto de Estudios Humanísticos "Juan Ignacio Molina”, Universidad de Talca. Talca, Chile. Correo electrónico: jpinedo@utalca.cl
}

Artículo recibido el 29 de mayo de 2014. Aceptado el 1 de julio de 2014. 


\begin{abstract}
The article exposes the meaning and use of the concept of postcoloniality by the intellectuals of the India and its adaptation in Latin America, especially by the Latin American Subaltern Studies Group (1995), to establish similarities and differences in the way some and others used this concept to analyze their respective colonial times and its present. We postulate that South Asian intellectuals started his reflection from the social and political reality to try to resolve the situation of the subordinate of his country immediately after independence in 1947, defined as marginal beings possessors of an ancient culture that nobody but themselves have access, and at the same time deprived of all rights of the enlightened modernity. Intellectuals in Latin America, in contrast, with the exception of Florencia Mallon, José Rabasa works and some others, possess a more academic of the subaltern view, and act as a statement of position to the inside of the intellectual history, distancing himself from the original historiography for focus on a defense epistemological against modernity and the system world.
\end{abstract}

Keywords: Latin America, India, postcoloniality, subject subordinate, peripheral thought.

\title{
POSTCOLONIALIDAD Y CONTEXTO MUNDIAL
}

El concepto postcolonialidad tiene su origen entre los pensadores de la India para describir la situación de su país después del colonialismo británico en 1947 y que planteaba una situación radicalmente nueva: ¿cómo enfrentar el futuro en un país con una fuerte identidad pero sometido a códigos económicos, políticos y culturales impuestos por el colonialismo? Y especialmente, se preguntaban, cómo integrar, o no, a las grandes masas de desposeídos a los procesos de modernización imperantes en Occidente. Es decir, una visión de la postcolonialidad no percibida sólo como un proceso de liberación sino también como un conflicto de integración o marginalización en el más tarde denominado "sistema mundo"

Estos planteamientos se extendieron rápidamente a otros países en condiciones similares ${ }^{2}$, pues desde los años 50 se evidencia en el mundo la presencia cada vez mayor de los países periféricos, muchos de ellos como repúblicas recién

\footnotetext{
${ }^{1}$ Ver, Wallerstein, Immanuel. El moderno sistema mundial, 1979. Mignolo, Walter. La idea de América. La herida colonial y la opción decolonial. Barcelona: Gedisa, 2007.

${ }^{2}$ Los historiadores indios se constituyen como grupo en tono a la la revista Subaltern Studies, fundada por Ranahit Guha en 1982, en la que analizan el impacto del colonialismo británico en la sociedad india, así como ciertas formas de reacción en su contra. Por su parte, la "Declaración de fundación del Grupo de Estudios Subalternos Latinoamericanos" (también llamado "Manifiesto inaugural") se da a conocer en 1995. Ver Beverley, John, Oviedo, José and Michael Monna (eds.), The Postmodernism Debate in Latin America. Durham: Duke University Press, (1995): 135-146.
} 
independizadas. Estas nuevas realidades políticas (Egipto, India, China, Vietnam, Senegal) tenían siglos de existencia y expresiones económicas y culturales propias y se encontraron con dificultades similares para enfrentar el mundo moderno ${ }^{3}$. Una posición que llegó incluso a la Europa de Jean Paul Sartre quien asumió como propias las políticas del Tercer Mundo 4 , y desde París clamó por la descolonización de la América Latina y de las colonias francesas en general.

En América Latina el concepto postcolonialidad tuvo una amplia recepción y desarrollo entre sus pensadores 5 quienes recurrieron a él para explicar el lugar político y cultural del continente en el mundo globalizado, y establecer nuevas relaciones con el pensamiento periférico denunciando las formas de colonialismo sobrevivientes. En ambos casos, India y América, pusieron en relieve la figura del sujeto subalterno ${ }^{6}$ como el gran perjudicado durante la época colonial pero también en la era republicana. En ambos casos, India y América Latina, se trataba de levantar una nueva concepción de la historia que les permitiera pensar desde sí mismos y relativizar la mirada eurocéntrica. Fue lo que escribió Guha, al criticar los metarrelatos y el discurso de la élite:

Lo que queda claramente fuera de esta historiografía ahistórica es la politica del pueblo. Porque, paralelamente a la esfera de influencia de la política de élite, existió a lo largo del periodo colonial otra esfera de la política india, en la que los actores principales no eran los grupos dominantes de la sociedad indígena ni las autoridades coloniales, sino las clases y los grupos subalternos que constituían la masa de la población trabajadora y el estrato intermedio de la ciudad y el campo, en suma, el pueblo (Guha, 1996: 1-8).

\footnotetext{
${ }^{3}$ En el año 2011 se cumplieron cincuenta años del inicio de la descolonización de África, sesenta y cuatro desde la independencia de India, fecha similar para China, y doscientos de la latinoamericana. Ver, Young, Robert J.C. Postcolonialism. An historical introduction. UK: Blackwell Publishing, 2001. ${ }^{4}$ Sartre, Jean-Paul. Colonialismo y neocolonialismo. Situations V. Buenos Aires: Losada, 1965. Ver, además, su prólogo a Los Condenados de la tierra, de Fanon, donde hace suyas las proclamas de la descolonización del Tercer Mundo (1961).

${ }^{5}$ Utilizo indistintamente los conceptos de intelectual, pensador y académico pues los autores tratados son "intelectuales" (más sistemáticos), "pensadores" (más ensayísticos), que laboran como "académicos" en universidades. Si hubiera que asignar alguna nominación propongo la que realiza Z. Bauman entre intelectuales "legisladores" e "intérpretes" e incluyo entre los primeros a los que analizamos aquí. Recomiendo el texto de Mabel Morańa and Bret Gustafson (eds.), Rethinking Intellectuals in Latin America, Iberoamericana, 2010, que incluye una importante cantidad de reflexiones sobre el tema. Y el de Carlos Altamirano. Intelectuales. Notas de investigación. Bogotá: Norma, 2006.

${ }^{6}$ El subalterno representa al sujeto social de rango inferior por razones sociales, de raza, género o cualquier otra.
} 


\section{ALGUNOS RASGOS DE LOS ESTUDIOS POSTCOLONIALES EN INDIA}

Lo que intentaron los intelectuales indios (Ranajit Guha, Gayatri Spivak, Partha Chatterjee, Dipesh Chakrabarty), como hemos dicho, fue la recuperación de la figura del subalterno como un sujeto social sin voz, y del que nadie puede hablar en su lugar ni representarlo política e historiográficamente. Esto produjo un estrangulamiento ideológico debido a que la Independencia nace con la frustración que significa el paso de una dominación extranjera a una dominación nacional, marcada por una situación socialmente circular, pues las nuevas repúblicas independientes continúan reproduciendo las antiguas formas culturales del dominador, asumidas ahora de forma voluntaria por el nuevo grupo dirigente.

Es decir, que el colonialismo no cesa de existir cuando el colonizador se retira conservando por un tiempo prolongado un imaginario social y cultural que obedece a los códigos de la dominación anterior. Al mismo tiempo y casi paradójicamente, se afirma que la dominación nunca es absoluta, pues aún en los peores momentos, el dominado mantiene espacios mentales propios (Guha, 1996). Así, además de las denuncias al colonialismo se observan las críticas a la propia sociedad india por las injusticias del presente como, por ejemplo, en su modo de actuar hacia las mujeres, que antes, durante y después de los británicos fueron maltratadas, en una doble dominación, por el poder extranjero y por los varones.

En este mismo sentido, es interesante destacar la relación de amor-odio con el colonizador, no sólo hacia el británico sino también con el portugués desde la llegada misma de Vasco da Gama en 1498, apenas seis años después que Colón al Nuevo Mundo. Partha Chatterjee para explicar esta dependencia asumida, recurre a la explicación de Maquiavelo, quien frente a la pregunta de cómo debe actuar el príncipe frente al súbdito, si provocando en este una actitud de temor o de admiración, responde que ambas, lo que se constituyó en una estrategia portuguesa exitosa (2008: 23) y que fue continuada más tarde por los británicos quienes a través del miedo pero también por la admiración hacia su cultura tecnológica provocaron la aceptación del Imperio.

Por último, se presenta a la India como una nación radicalmente diferente a la sociedad moderna y se considera al nacionalismo como una fuerza social que en el Tercer Mundo puede ser liberadora con una concepción no necesariamente conservadora como lo ha sido tradicionalmente en la sociedad occidental. Una ideología con que los oprimidos buscan su liberación del dominio foráneo.

Ante esta multiplicidad de perspectivas, el concepto postcolonialidad posee variadas definiciones y recurro a lo planteado por el Diccionario de Filosofía Latinoamericana que lo define en su acepción temporal, discursiva y epistémica:

En su acepción temporal, el poscolonialismo aparece como un período histórico iniciado en 1947 (con la independencia de India), una vez finalizada la Segunda 
Guerra Mundial, cuando se quebrantaron los fundamentos geopolíticos del orden colonialista establecidos por Europa desde el siglo XVI (P. Williams, L. Chrisman). Los procesos emancipatorios en Asia y en África, la aparición de los nacionalismos del "Tercer Mundo" y su inscripción ambigua en las zonas de influencia definidas por la Guerra Fría, así como el éxodo masivo de inmigrantes hacia los países industrializados, serían algunas de las características del período poscolonial (F. Jameson). En su acepción discursiva, el poscolonialismo hace referencia a las literaturas producidas en los territorios ocupados durante todo el período colonial (B. Ashcroft), o bien a las prácticas discursivas contrahegemónicas que lograron quebrantar o desplazar los saberes utilizados por Europa para legitimar su dominio (E. Shoat, M. L. Pratt). Finalmente, la acepción epistémica del poscolonialismo tiene que ver con las llamadas "teorías poscoloniales" surgidas durante los años ochenta en Inglaterra y los Estados Unidos. Las pautas centrales de estas teorías fueron definidas por el palestinense Edward Said, quien en su libro Orientalism (1978) inició una genealogía de los saberes europeos sobre el "otro", mostrando los vínculos entre ciencias humanas e imperialismo. Este camino fue seguido rápidamente por académicos indios (G. Spivak, H. Bhabha, R. Guha), surafricanos (B. Parry), árabes (A. Aijaz) y latinoamericanos (W. Mignolo) ${ }^{7}$.

El impacto de las ideas del Grupo Estudios Subalternos en América Latina produjeron una gran movilización del pensamiento y una alta productividad intelectual similar al influjo del historicismo de Ortega y Gasset en los ańos 20 y 30, al neomarxismo de los 60 y 70, el concepto de "Real maravilloso" durante el boom literario; o al debate identidad/modernidad en los 80: es decir, fueron ideas percibidas como nuevos criterios para leer la realidad del continente americano lo que ha producido gran cantidad de publicaciones, seminarios y congresos académicos, tesis universitarias, diccionarios y manuales. Su presencia era la prueba, además, de que las humanidades podían abandonar su condición de "ciencias blandas" al presentar ahora criterios científicos sólidos para analizar la realidad política, social y cultural, que permitían superar las interpretaciones "impresionistas" de la ensayística latinoamericana anterior.

\section{ANTECEDENTES LATINOAMERICANOS DE LA POSTCOLONIALIDAD}

Aunque algunos latinoamericanistas dieron origen a fines de los años $90 \mathrm{y}$ comienzos del siglo XXI (Santiago Castro-Gómez, Eduardo Mendieta, John Beverley, Javier Sanjinés, Ileana Rodríguez, José Rabasa, Aníbal Quijano, Catherine Walsh), al grupo Modernidad/Colonialidad (Aníbal Quijano, Edgardo Lander, Ramón

\footnotetext{
${ }^{7}$ En: http://www.cialc.unam.mx/pensamientoycultura/biblioteca\%20virtual/diccionario/poscolonialismo. htm [Consultado: el 17 de mayo de 2012].
} 
Grosfoguel, Walter Mignolo, Catherine Walsh, Arturo Escobar y Fernando Coronil, Enrique Dussel, Santiago Castro-Gómez, y Nelson Maldonado-Torres, a los que se sumaron algunos de los anteriores), creyeron ver en los estudios postcoloniales el inicio casi adánico de una nueva era metodológica en la forma de comprender la realidad del Continente ${ }^{8}$, en realidad existen múltiples antecedentes de la presencia de esta teoría en el pensamiento latinoamericano anterior, aunque es cierto que los pensadores indios la sistematizaron de un modo más coherente.

En efecto, desde los ańos 30 y 40 una parte de la intelectualidad de América Latina se sintió ligada a los movimientos independentistas del Tercer Mundo por el rechazo común al imperialismo, lo que produjo un amplio campo ideológico en el que confluyeron las ideas de Mariátegui, las reflexiones de Aimé Cesaire y las preguntas de Frantz Fanon sobre la condición del caribeño, los escritos de Eric Williams, las publicaciones del "Pensamiento latinoamericano" (Zea, Roig, Ardao) y, más tarde, de la Teología y Filosofía de la Liberación de los años 60 y 70.

Además, se debe mencionar las propuestas de Rodolfo Kusch y sus estudios sobre el pensamiento indígena y popular, las de Darcy Ribeiro y el proceso civilizatorio en América Latina, así como las de Fernando Ortiz y especialmente de Roberto Fernández Retamar cuyos textos podemos considerar poscoloniales avant-la-lettre, porque relativizan el saber europeo como único capaz de producir conocimiento filosófico.

Antecedentes que podemos rastrear más atrás aún, en Simón Bolívar, Francisco Bilbao, quienes reclamaron la necesidad de una "Segunda Independencia", siendo José Martí el creador del concepto e iniciador de esta corriente intelectual que establecía el continuismo de dominación entre el mundo colonial y el de la postindependencia, y la denuncia del nuevo imperio representado por los EE.UU.

José Carlos Mariátegui, en sus 7 ensayos de interpretación de la realidad peruana, (1928), observa al Virreinato como una situación histórica que a pesar de estar concluida, mantenía una presencia que afectaba la (difícil) identidad nacional peruana?.

\footnotetext{
8 Ver, por ejemplo, la "Declaración de fundación del Grupo de Estudios Subalternos Latinoamericanos" (1995), que analizamos más adelante.

${ }^{9}$ Mariátegui no sólo critica al imperio español sino a la época republicana, y a su propio presente por el desconocimiento que se hace del indio y del mestizo: "La educación nacional, por consiguiente, no tiene un espíritu nacional: tienen más bien un espíritu colonial y colonizador. Cuando en sus programas de instrucción pública el Estado se refiere a los indios, no se refiere a ellos como peruanos iguales a todos los demás. Los considera como una raza inferior. La República no se diferencia en este terreno del Virreinato". Y más adelante: "La economía del Perú es una economía colonial. Su movimiento, su desarrollo, están subordinados a los intereses y a las necesidades de los mercados de Londres y de Nueva York". Ver: Mariátegui, José Carlos. 7 Ensayos de interpretación de la realidad peruana. Caracas: Biblioteca Ayacucho, (2007): 8.
} 
Esta postura fue más tarde recogida y continuada por Leopoldo Zea que se propuso el desafío de levantar una filosofía que permitiera alcanzar el "nosotros mismos", algo difícil de definir en América Latina, y recurre al mismo concepto de descolonización:

La salvación, la descolonización del hombre y la cultura de que somos parte y expresión, ha de venir de nosotros mismos [...] Potenciando al hombre que de alguna manera ha existido, el que ha hecho la historia, nuestra historia; una historia que no puede ser ya la de los colonizadores sino de los colonizados que luchan por un mundo en que dejan de existir los unos y los otros ${ }^{10}$.

Para Zea, con la "Segunda Independencia" no se recupera al sujeto que vivió la colonización sino a un tercero, distinto y nuevo, que es producto de los anteriores, el colonizador y el colonizado, y que es la prueba de un positivo mestizaje racial y cultural ${ }^{11}$.

Zea, como Arturo Andrés Roig, Arturo Ardao, Pablo González Casanova, Felipe Herrera, José Luis Romero, Paulo Freire, Augusto Salazar Bondy, y muchos otros, tomaron conciencia de pertenecer a la periferia, pero negando el esquema "Civilización y Barbarie", el que invirtieron incluyéndose ellos mismos entre los bárbaros para mirar a Occidente de una manera no imitativa. De aquí la necesidad que proclamaron de reinventarse desde sí mismo, siguiendo la muy antigua consigna de Simón Rodríguez: "O inventamos o erramos"12.

Es decir, hay un continuum entre los antecedentes mencionados y las posteriores teorías de la postcolonialidad y desconocer estos esfuerzos previos puede resultar injusto, al seńalar que desde el punto de vista del subalterno nada ha cambiado con las posiciones progresistas o conservadoras, pues la condición de aquél se ha mantenido inalterable ${ }^{13}$.

${ }^{10}$ Zea, Leopoldo. "El pensamiento latinoamericano. Latinoamérica en busca de su identidad”, En http://www.ensayistas.org/filosofos/mexico/zea/pla/3-3.htm. [Consultado: el 14 de abril de 2012]. Ver además: Zea, Leopoldo. Discurso desde la marginación y la barbarie. Barcelona: Anthropos, 1988. En el mismo sentido Arturo A. Roig publica. Teoría y crítica del pensamiento latinoamericano (1981), en el que los dos capítulos iniciales se titulan: "Acerca de la significación del 'nosotros'” y "La historia del 'nosotros' y de lo 'nuestro".

${ }^{11}$ Ver: Pinedo, Javier. "El concepto Segunda Independencia en la historia de las ideas en América Latina: Una mirada desde el Bicentenario", Revista Atenea, Universidad de Concepción, N 502- II Semestre, (2010): 151-177.

12 “¿Dónde iremos a buscar modelos? La América Española es original. Originales han de ser sus instituciones y su gobierno. Y originales los medios de fundar unos y otros. O inventamos o erramos". Rodríguez, Simón. Sociedades Americanas, [1828], Fundación Biblioteca Ayacucho, Caracas, 1990.

${ }^{13}$ José Rabasa reconoce este continuum y cita como antecedentes los trabajos de Albert Memmi, Aimé Césaire, Amílcar Cabral, Fanon y de Mariátegui, entre otros. Rabasa, José. "Poscolonialismo". En Mónica Szurmuk y Robert Mckee. Diccionario de Estudios Culturales Latinoamericanos. México: siglo XXI, (2009): 219-223. 
A su vez, algunos conceptos utilizados por los pensadores de la India habían sido creadas en América Latina como las categorías de "centro" y "periferia" (Ernest Wagemann, Celso Furtado), la Teoría de la dependencia (Fernando H. Cardoso, Enzo Faletto), la Teoría de la Modernización (Gino Germani), y otros que determinaban el lugar desde el cual se asumía una modernidad temida pero deseada.

El propio Guha usa la expresión "semi feudal society under colonial rule" (Guha, 1983) ${ }^{14}$ y aunque no podemos saber si en su pensamiento influyó alguna lectura latinoamericana, sí es cierto que esa expresión fue muy utilizada en las reflexiones latinoamericanas de los años 60 por André Gunder Frank, sobre la condición feudal, semifeudal o capitalista de América Latina y que marcaron el debate sobre el carácter histórico-económico de la conquista española. Frank en sus libros, Capitalismo y subdesarrollo en América Latina (1967) y Lumpenburguesía: Lumpendesarrollo. Dependencia, clase y política en Latinoamérica, (1972), plantea que desde el inicio mismo de la conquista hispana, América Latina se integró a un capitalismo dependiente causante de su pobreza, y por tanto el paso natural de su liberación era pasar directamente al socialismo. Esta interpretación fue rechazada por sectores de la izquierda reformista que postulaban la necesidad de realizar revoluciones burguesas previas a través de una política de alianzas de clases, como etapas necesarias antes de dar el salto al socialismo ${ }^{15}$.

Estos debates cruzaron las fronteras latinoamericanas y se instalaron entre los pensadores del Caribe, y más tarde en África, y en algunas universidades europeas. Algunos de esos conceptos debieron llegar a Guha y los otros fundadores del G.E.S, que los acogieron por tratarse de una situación política y económica común: por una parte la dependencia inglesa y por otra la dependencia hispana y norteamericana más tarde, con efectos igualmente similares: lejanía del centro occidental y de los fundamentos de la modernidad: democracia, emancipación individual, ciudadanía, y un común subdesarrollo económico provocado por la expoliación extranjera ${ }^{16}$.

Otro antecedente todavía se encuentra en la categoría "liberación" (en filosofía y teología), que postulaba un "compromiso" con el cambio social y una

${ }^{14}$ Guha, Ranajit. "Elementary Aspects of Peasant insurgency in Colonial India", Journal of Asian Studies, 1983. Citado por Beverley, John. Subalternity and Representation. Durham and London: Duke University Press, (1999): xiii.

${ }^{15}$ Algunos críticos de André Gunder Frank fueron, Aníbal Pinto, "Diagnóstico y «catastrofismo» en el continente", en Tres ensayos sobre Chile y América Latina. Buenos Aires: Ediciones Solar, (1971): 1020. Laclau, Ernesto. "Feudalism and Capitalism in Latin America", New Left Review, No 67, Londres, mayo-junio, (1971): 19-38. Entre los defensores, los teóricos cubanos de la revolución y especialmente el grupo troskista ligado a Paul Baran y Paul Sweezy, de la Monthly Review, y el historiador Luis Vitale, Interpretación marxista de la Historia de Chile, VII tomos publicados entre 1967 y el año 2000.

${ }^{16}$ Devés-Valdés, Eduardo. Pensamiento Periférico. Asia - África - América Latina - Eurasia y algo más. Una tesis interpretativa global. Santiago de Chile: IDEA - USACH, 2012. 
búsqueda de "independencia" real de las masas populares y su acceso a la libertad política y económica por medio de la acción de diversos actores sociales entre los cuales los intelectuales jugaban un rol central ${ }^{17}$.

Las referencias mencionadas tuvieron su máxima expresión política en la Revolución cubana (1959), la Unidad Popular chilena (1970-1973), el entusiasmo que provocó el regreso de Perón a Buenos Aires (1973), la revolución sandinista (1978) y una cantidad de movimientos de izquierda a lo largo del continente, más o menos fracasados por los golpes militares de mediados de los años 70, los que hicieron que la actividad intelectual latinoamericana se volviera más "escéptica" en medio de sociedades sometidas al rigor del neoliberalismo, lo que coincidió con la aparición en Europa de la postmodernidad, la desconstrucción y el pensamiento débil, que fueron bien acogidos por sectores que postulaban que las utopías sociales habían llegado a su fin.

Sin embargo, el pensamiento "liberacionista" no desapareció del todo pues se reactualizó, en parte, a través de los Estudios Culturales alentados por Raymond Williams y otros del Círculo de Birmingham, que pusieron, aunque de manera diferente, en lo marginal (mujeres, migrantes, minorías étnicas y sexuales) el objetivo de sus análisis académicos.

Los Estudios Culturales, que como los Estudios subalternos, llegaron vía Inglaterra y Estados Unidos a Iberoamérica, no fueron aceptados por todos los pensadores latinoamericanos pues en muchos casos, en un ambiente contradictoriamente influido por las lecturas de Baudrillard, Jameson, Derrida, autores como Arturo A. Roig y Enrique Dussell los culparon de ocultar las contradicciones sociales que al recuperar otros sujetos marginales (emigrantes, mujeres, minorías sexuales), dejaban fuera a obreros y campesinos. O bien, se opusieron a la indiferencia de los Estudios Culturales por el análisis de las obras canónicas de la literatura espańola e hispanoamericana, dando preferencia a las lecturas de los textos recientes basados en sujetos de frontera. En este contexto de fuerte innovación metodológica, en el que todos parecían ganar menos las antiguas interpretaciones sesentistas, los Estudios Culturales fueron vistos por sus críticos como el último esfuerzo de las universidades norteamericanas por recuperar, con análisis tibiamente críticos, el tiempo perdido, por lo que recibieron muchas críticas de aquellos que preferían análisis más "comprometidos" con el mundo social ${ }^{18}$, para quienes resultaba una paradoja recurrir a interpretaciones estadounidenses o europeas para analizar la

\footnotetext{
${ }^{17}$ Ver, Dussel, Enrique. Filosofía de la liberación. México: Edicol, 1977. Scannone, Juan Carlos. "La filosofía de la liberación: Historia, características, vigencia actual”, Teología y Vida, PUC., Vol. L (2009): 59-73.

${ }^{18}$ José Rabasa incluye en un comienzo al Poscolonialismo al interior de los Estudios Culturales y no como un área de estudio autónoma: "Entre los términos más debatidos en los estudios culturales latinoamericanos, en los últimos veinticinco años, figura el del Poscolonialismo, en parte por su manufactura en lengua inglesa pero también por su desfase histórico". Rabasa, José. "Poscolonialismo", op. cit. 220.
} 
realidad de la América Latina. En este escenario surgió un nuevo interés por la figura del "marginal" como opositor a la sociedad militarizada de los años 70 y 80 , y a su modelo del "emprendedor" neoliberal. Y por otro lado, se le comenzó a dar gran importancia a las consecuencias de la colonia en la vida de los países que la sufrieron por lo que se habla de "Modernidades coloniales" o de "Otras Modernidades"19, abriendo el análisis, en el marco de la discusión identidad-modernidad de los ańos 80 y 90, sobre qué es la modernidad y el modo como se estructura en los países periféricos; concepto asociado, además, al de "modernidades múltiples" (Eisenstadt, 2000), surgido en torno a la pregunta de si existe una forma esencial de modernidad, o muchas expresiones de ella, una de las cuales sería la modernidad postcolonial, lo que reafirmó la conflictiva relación de Latinoamérica y el proyecto ilustrado.

En este contexto de dudas y búsquedas metodológicas la llegada de las teorías de la subalternidad desde la India ${ }^{20}$, fueron acogidas como una tabla de salvación entre los latinoamericanistas por la necesidad de contar con una epistemología nueva que permitiría resolver tres cuestiones fundamentales: 1. Superar el vacío intelectual dejado por las posiciones "liberacionistas", 2. Aglutinar los cabos sueltos de diversas posiciones académicas aisladas: postmodernidad, estudios culturales, feminismo, Walter Benjamin, la desconstrucción, y 3 . Recuperar un nuevo compromiso con el mundo social.

Como hemos dicho, los teóricos de la subalternidad latinoamericana vieron las propuestas de los pensadores indios como una nueva metodología de análisis, fresca y atractiva en un momento de crisis de los paradigmas académicos de los ańos 80, lo que les permitió reflotar un nuevo lugar para las ciencias sociales en América Latina y creyeron que con ellos se llegaba al fin de los debates metodológicos, pensando que la teoría postcolonial les permitiría alcanzar un reencantamiento en el propio quehacer de las humanidades y las ciencias sociales con nuevas perspectivas analíticas, pero también como una oportunidad de revalorizar los estudios sobre América Latina y creyeron poder resolver conceptualmente, las contradicciones de la compleja realidad del continente. La postcolonialidad se asoció a un debate sobre un "cambio de paradigma" que abría metodologías radicalmente nuevas para

\footnotetext{
${ }^{19}$ Ver, Dube, Saurabh, Ishita, Banarjee y Mignolo, Walter. Modernidades coloniales. México: El Colegio de México, 2004. De los mismos autores ver también, Otras modernidades. México: El Colegio de México, 2011.

${ }^{20}$ Como dijimos, estas ideas llegaron desde Inglaterra y más tarde desde los Estados Unidos. José Rabasa nos entrega un valioso antecedente: "La conferencia sobre "Europa y sus otros" (Europe and Its Others) en la Universidad de Essex, Inglaterra, en 1984, constituyó un primer momento en el que se planteó el proyecto poscolonial en el ámbito académico. Entre los participantes figuraron Edward Said, Gayatri Spivak, Homi Bhabha, Peter Hulme, Talal Asad, y, en el área de los estudios culturales latinoamericanos, Gordon Brotherston, Doris Sommer y José Rabasa "Poscolonialismo", op. cit. 220.
} 
el análisis de la realidad social y cultural latinoamericana y del Tercer Mundo ${ }^{21}$, sumándose a otros conceptos que flotaban en el ambiente como "Modernidad periférica", "Identidad fracturada", "Premodernidad", "Archivos de la Memoria", "Construcción de la Nación", "Ciudadanía global".

Pero sobre todo, la postcolonialidad fue vista como una metodología que permitía ubicar a los estudiosos latinoamericanos en igualdad de condiciones con el horizonte intelectual europeo y norteamericano, lo que sería una motivación fundamental del posterior grupo Modernidad/Colonialidad, particularmente en los trabajos de Dussel y Mignolo.

Por otro lado, la insistencia de los pensadores de India en poner al sujeto subalterno como tema central de sus reflexiones, sujeto social que en América Latina aunque siempre presente, había decaído por la presencia del neoliberalismo económico y el contexto político conservador de los años 80 , permitió recuperar de nuevo esas voces ocultas, aunque en una escala menor que los indios, como por ejemplo, en la perspectiva del Grupo de Estudios Subalternos Latinoamericanos, que aunque realizaron escasos trabajos de archivos como sugerían los autores indios, para evitar que fueran los intelectuales quienes tomaran la voz de los subalternos, se proponían lograr que fueran estos mismos los que contaran su propia historia sólo alcanzable en los lugares donde habían dejado sus testimonios: archivos judiciales, memorias, relatos autobiográficos ${ }^{22}$.

El aporte académico de los estudios postcoloniales ha sido reconocido por algunos de sus destacados representantes:

La crítica postcolonial que surge en los años ochenta se propone transformar el saber académico. El concepto de orientalismo de Said tuvo efectos globales en los estudios sobre África, Asia y Oceanía. Ya no se podría pensar, sin tomar en conciencia de los orígenes imperialistas de las tradiciones intelectuales occidentales,

\footnotetext{
${ }^{21}$ Ver, de Toro, Alfonso. "La Postcolonialidad en Latinoamérica en la era de la globalización ¿Cambio de paradigma en el pensamiento teórico-cultural latinoamericano?”. En Alfonso de Toro y Fernando de Toro (eds.), El debate de la postcolonialidad en Latinoamérica. Una postmodernidad periférica o Cambio de paradigma en el pensamiento latinoamericano. Frankfurt am Main: Vervuert, (1999): 31-77.

${ }^{22}$ Efectivamente existen pocos trabajos de campo entre los postcolonialistas latinoamericanos y las excepciones son las investigaciones de Florencia Mallon, Campesinado y nación. La construcción de México y Perú postcoloniales. México: CIESAS, Colegio de Michoacán y Colegio de San Luis de Potosí, 2003. Mallon, Florencia. La sangre del copihue. La comunidad mapuche de Nicolás Ailio y el Estado chileno, 1906-2001. Santiago de Chile: Lom, 2005. Y algunos textos de José Rabasa, Writing Violence on the Northern Frontier: The Historiography of Sixteenth-Century New Mexico and Florida and the Legacy of Conquest (Latin America Otherwise: Languages, Empires, Nations), 2000. Rabasa, José. "Revolutionary Spiritualities in Chiapas Today: Immanent History and the Comparative Frame in Subaltern Studies". In Jerome Branche and Elizabeth Monasterios (eds.), Race, Coloniality, and Social Transformation. Gainsville: University of Florida Press, (2008): 160-203.
} 
directa o indirectamente imbricadas en el colonialismo, no solo en el contexto de las antiguas metrópolis sino también en la exportación de los antiguos paradigmas a países como México, donde todavía está por escribirse la historia de los centros de estudios de África y Asia en el Colegio de México ${ }^{23}$.

Y en relación con el tema propiamente de la subalternidad, queda claro, que para Beverley, por ejemplo, es un tema de debate inter intelectuales. Beverley toma partido a favor de los pensadores cercanos al mundo "nacional-popular" de Gramsci, y en contra del que denomina intelectual "neo-arielista”. Es fácil coincidir con él y su pensamiento político progresista, posterior a la decepción postmoderna. Sin embargo, del punto de vista del tema que nos convoca, Beverley nos comprueba que en su caso la trayectoria del pensamiento postcolonial visualizado desde un latinoamericanista norteamericano, tienen como objetivo encontrar una pragmática útil para modificar la realidad de ambas Américas: en la del sur liberar a los grupos subalternos; en la del norte, lograr que los EE.UU., se abran a grupos de inmigrantes cuya presencia, en aumento, permitirá completar la identidad fundacional de la república de las barras y las estrellas. Es decir, se trata finalmente de una reflexión sobre el "poder, quién lo tiene y quién no, quién lo está ganando y quién lo está perdiendo" ${ }^{24}$, un objetivo que concluye por traducirse en una reflexión académica o de "teoría cultural" para usar el concepto del título de su libro. Así, en la postcolonialidad latinoamericana se cruza una dimensión más cercana a una reflexión global sobre las Américas a comienzos del siglo XXI, y especialmente sobre el rol de los intelectuales y las universidades en esa reflexión, y en la que el sujeto subalterno está presente pero de una manera lejanamente inspiradora.

Muy interesantes resulta los detalles que entrega John Beverley sobre el modo cómo se instituyó el Grupo de Estudios confirmándonos que él y otros de sus miembros iniciales llegaron a esa disciplina por el fracaso y descarte de otras áreas de análisis y especialmente por la crisis de la militancia de izquierda de la época:

Fue por esta crisis en mi trabajo y mis compromisos políticos - pero también como una forma de rescate de ese trabajo y esos compromisos- que yo giré hacia los estudios subalternos. Me encontré con otros latinoamericanistas en ese tiempo (habla de más o menos de 1990) que comenzaban a tener noticias del Grupo de Estudio Subalternos de Asia del Sur e imaginaban que ese grupo tenía una relación más que casual con nuestras propias preocupaciones.

Y más adelante:

\footnotetext{
${ }^{23}$ Rabasa, José, op. cit. 220.

${ }^{24}$ Beverley, John. Prólogo. "Al lector latinoamericano", e "Introducción", de la traducción española de su libro, Subalternidad y Representación. Debates en teoría cultural. Madrid: Iberoamericana/Vervuert, (2004): 23.
} 
Tomando la idea de los estudios subalternos y la forma organizacional de un colectivo académico del grupo sudasiático decidimos fundar una organización similar en los estudios latinoamericanos. Nos reunimos por primera vez en la George Mason University, cerca de Washington DC, en abril de 1992, de tal reunión surgió un documento fundacional -originalmente escrito como una propuesta para la Fundación Rockefeller- en la cual definíamos la necesidad de un nuevo paradigma [... $]^{25}$.

Queda claro, en los comentarios de Beverley, el camino opuesto al de los pensadores indios, es decir no se parte de la realidad social a su difusión académica posterior, sino al contrario: "Nuestro impulso fue, de alguna manera, el inverso. Teníamos que ir desde la crítica y la teoría literaria hacia la historia social y la narrativa etnográfica para tratar la crisis que estaba comenzando en nuestro propio campo" ${ }^{26}$.

En fin de cuentas, la postcolonialidad les permitió a los intelectuales neo arielistas o no, vivir en un espacio geográfico, político y social marginal, pero revalorizado por un lenguaje y una visión de mundo que renovó las antiguas preguntas sobre el rol de América Latina en el mundo contemporáneo. Tal vez, pensaron que podrían ser académicos comprometidos y postcoloniales al mismo tiempo.

\section{EL GRUPO DE ESTUDIOS SUBALTERNOS LATINOAMERICANOS (G.E.S.La). LO DISCIPLINAR Y LO POLÍTICO}

Si analizamos la "Declaración de fundación del Grupo de Estudios Subalternos Latinoamericanos" ${ }^{27}$, vemos que en ella se exponen dos cuestiones

\footnotetext{
${ }^{25}$ Beverley, John, op. cit. 28.

${ }^{26}$ Beverley, John, op. cit. 30.

${ }^{27}$ Como he señalado en nota 4, la Declaración apareció en idioma inglés en John Beverley, José Oviedo, and Michael Monna (eds.), The Postmodernism Debate in Latin America. Durham: Duke University Press, (1995): 135-146. Utilizo la versión en español publicada como "Declaración de Fundación del Grupo de Estudios Subalternos Latinoamericanos" (traducción de Juan Zevallos Aguilar), Procesos. Revista Ecuatoriana de Historia, No 10, I semestre, (1997): 135-147; sin nombres de autores, aunque se sabe que participaron en su redacción, Walter Mignolo, Patricia Seed, Julio Ramos, Norma Alarcón y John Beverley. El texto de la revista Procesos se encuentra en http://repositorio.uasb.edu.ec/ bitstream/10644/1323/1/RP-10-Testimonio.pdf. Para un análisis histórico del tema ver, Zevallos Aguilar, Juan. "La introducción de los discursos colonial y postcolonial en los estudios latinoamericanos", en http://www.ic.nanzan-u.ac.jp/LATIN/kanko/PL/2007pdf/03_JUANZEVALLOSAGUILAR.pdf. El documento se reproduce en muchos sitios web, por ejemplo, http://www.ensayistas.org/critica/ teoria/castro/manifiesto.htm. Fue publicado un ańo después como "Manifiesto inaugural. Grupo Latinoamericano de Estudios Subalternos”. En Santiago Castro Gómez y Eduardo Mendieta (eds.), Teorias sin disciplina (latinoamericanismo, poscolonialidady globalización en debate). México: Miguel Ángel Porrúa, 1998. Para una lectura general sobre el tema, recomiendo Ludden, David. "A Brief History of Subalternity", En David Ludden (ed.), Subaltern Studies: Critical History, Contested Meaning, and the Globalisation of South Asia. New Delhi: Permanent Black, (2001): 1-39.
} 
fundamentales: una académica marcada por una gran confianza en la oportunidad de "revisar epistemologías establecidas y previamente funcionales en las ciencias sociales y las humanidades". Y otra política: la posibilidad de liberar de una vez por todas al subalterno latinoamericano. En este último sentido se trata de una reflexión sobre el "poder" y de cómo alcanzarlo. Según señala John Beverley, se trata de una posibilidad de cambio social con "hopes and passion", y "political consequences" (1999: 1), y una perspectiva que se identifica con posiciones políticas cercanas al mundo popular: "friends of the people" (1999: xi ${ }^{28}$.

Esta búsqueda de definiciones académicas y políticas, se observa, además, en la reflexión final que incorpora Beverley en la página con la que concluye su libro, Subalternity and Representation, ya mencionado:

There is no way of telling where the impulses that will revive the project of the left will come from, and there is no reason to suppose in advance that higher education today might not be what in the idiom of the Old left was called" a "key sector". But this also means assuming a new kind of responsibility for what we say and do. That is perhaps the most important lesson subaltern studies teaches us(1999: 167).

Es fácil observar en una lectura de la "Declaración de fundación" la cercanía que establecen los latinoamericanistas con los indios: "El trabajo del Grupo de Estudios Subalternos, una organización interdisciplinaria de académicos del Sur de Asia liderados por Ranajit Guha, nos ha inspirado a fundar un proyecto similar dedicado a estudiar lo subalterno en Latinoamérica”. Y más adelante señalan el estar viviendo en el continente en una situación social nueva marcada por "[...] el desmantelamiento de los regímenes autoritarios [...], el fin del comunismo y el consiguiente desplazamiento de los proyectos revolucionarios, los procesos de redemocratización y las nuevas dinámicas creadas por los medios masivos de comunicación y la transnacionalización económica”. Se requiere, concluyen, de "nuevas formas de pensar y actuar políticamente" (1997: 135).

Y desde la perspectiva del "subalterno", realizan críticas a los grupos conservadores dominantes, como a los progresistas que intentaron su liberación:

...las visiones del subalterno de las élites tanto del periodo colonial como del periodo de la posindependencia hicieron que el Grupo de Estudios Subalternos

\footnotetext{
${ }^{28}$ Beverley, John. Subalternity and Representation. Arguments in Cultural Theory. Durham and London: Duke University Press, 1999. Beverley cita entre otros a Gayatri Spivak: "Subaltern studies is about power, who has it and who doesn't, who is gaining it and who is losing". In "Can the Subaltern Speak?" Cary Nelson and Lawrence Grossberg (ed.), Marxism and the Interpretation of Culture. Urbana: University of Illinois Press, (1988): 271-313.
} 
(de la India) cuestione los paradigmas maestros usados en la representación de sociedades coloniales y postcoloniales en las prácticas culturales de hegemonía desarrolladas por los grupos de élite y en los discursos disciplinarios de las humanidades y las ciencias sociales que buscan representar el funcionamiento de esas sociedades (1997: 136).

En este sentido la "Declaración" analiza más el presente que el pasado colonial, pues ambos (pasado y presente) coinciden desde el punto de vista de la condición perjudicada del subalterno cuya presencia los lleva a dar por superadas las metodologías anteriores de análisis (las "historiografías colonial, nacionalista y marxista ortodoxa") que se igualan en la medida en que el subalterno no fue liberado por ninguna de estas teorías de análisis: "El aporte de Guha fue señalar que el subalterno, por definición no es representable como un sujeto histórico capaz de una acción hegemónica” (1997: 136 ${ }^{29}$.

Para indios y latinoamericanistas, las antiguas metodologías (de las élites o no) se desvirtúan, pues finalmente intentaban el control de las "poblaciones sometidas", incluidos "los discursos de los movimientos revolucionarios que buscan subvertir su poder en el nombre del "pueblo" (1997:137).

Los autores de la "Declaración", sintetizan la situación política latinoamericana del siglo XX, en tres fases marcadas por el fracaso en la emancipación del subalterno, desde el inicio mismo con la revolución mexicana que "marcó un punto de partida con un modelo eurocéntrico de desarrollo predominantemente blanco, masculino y oligárquico", [...] a favor del crecimiento de una clase media y alta mestiza, con la supresión de los líderes y comunidades indígenas y con la resubalternización del indígena" (1997: 138).

La cita anterior confirma la tesis según la cual la Independencia de América Latina fue un hecho beneficioso sólo para los grupos monopólicos terratenientes en desmedro de los populares que se mantuvieron en su misma situación de no integración social:

Como se sabe, aunque la mayoría de los países latinoamericanos ganaron su independencia formal en el siglo XIX, los estados-nación poscoloniales resultantes fueron dirigidos predominantemente por criollos blancos que desarrollaron regímenes de colonialismo interno con respecto a los indígenas, los esclavos de ascendencia africana, el campesinado, mestizo y mulato y los proletariados nacientes (1997: 137).

\footnotetext{
${ }^{29}$ La "Declaración" hace referencia al artículo de Ranajit Guha "The Prose of Counter Insurgency", Subalten Studies II. Delhi: Oxford University Press, (1983):1-42.
} 
Una realidad, según dicen, que iguala a la India dominada por las élites de la administración británica, con lo sucedido con los campesinos en el México de comienzos de siglo y de otros países del Continente, pues se establece un elemento común: el subyugamiento de las clases populares.

Una situación similar observan respecto a la revolución cubana que aunque "representó un renacimiento parcial del impulso de sacar a la superficie al subalterno", como por ejemplo, en la "relectura que hace Roberto Fernández Retamar de Fanon y el discurso de liberación nacional en su ensayo Caliban” (1997: 138). Sin embargo, ese esfuerzo resultó parcial e incompleto, pues aunque el método de análisis cubano:

[...] comprometía problemas de género, raza y lenguaje, y su insistencia en un sujeto unitario de clase y la asunción concomitante de la identidad en textos teórico literarios producidos por elites intelectuales que trataban este asunto borraban la disparidad de negros, indígenas, chicanos y mujeres; modelos alternativos de sexualidad y del cuerpo; epistemologías y ontologías alternativas; la existencia de aquellos que no habían entrado todavía en el pacto social con el estado (revolucionario); el 'lumpen'(1997: 139).

En lo que denominan como "Segunda Fase: 1968-1979" insisten en que ninguna de las alternativas de liberación surgidas hasta el momento han logrado su objetivo, incluido al propio Che Guevara, cuyo proyecto fracasa en Bolivia al no poder situarse en el lugar del indígena: "[...] el reconocimiento del Che, anotado en el Diario en Bolivia, de los ojos inexpresivos de los campesinos aymara hablantes del altiplano que él estaba tratando de organizar" (1997:139). Unos ojos que el Che no podía comprender ni asumir sus sueños.

Es cierto que valoran las expresiones críticas de aquella época como la:

Nueva Izquierda estadounidense y el movimiento contra la guerra de Vietnam, el 'Mayo' francés y las manifestaciones estudiantiles y la posterior masacre de Tlatelolco en México en 1968; es decir, el ingreso de los estudiantes como actores políticos en el escenario mundial, desplazando a los partidos y formaciones social demócratas y comunistas tradicionales (1997: 139).

Pero, se trata de una fuerza nueva estudiantil que tampoco logró su objetivo emancipador.

En esta revisión histórica realizan un breve análisis de la llegada a Latinoamérica de la teoría posestructuralista francesa, el marxismo gramsciano y la herencia de la Escuela de Frankfurt, así como del "trabajo de Bakhtin, Voloshinov, Lotman y la Escuela de Tartu y el campo emergente de los estudios culturales en los Estados Unidos y Gran Bretaña" (1997:140), todas igualadas en el hecho de representar ideologías nuevas pero igualmente insuficientes. 
Con lo anterior la "Declaración" se vuelve una exposición de la Historia intelectual de los últimos 50 años, vista desde una mirada nueva: la del subalterno, y desde el cual se da por concluido el marxismo, el estructuralismo y la postmodernidad, movimientos que se aglutinan en un denominador común: el haber mantenido al subordinado al margen de sus reflexiones y prácticas liberacionistas. Y a lo más reconocen algunos movimientos populares, pero muy pocas figuras intelectuales con lo cual se suman a una típica característica de los movimientos intelectuales latinoamericanos: su antiintelectualismo.

Finalmente, en la calificada como "Tercera Fase", que corresponde a los ańos ochenta del siglo XX, mantienen su postura inicial: nada hasta ahora ha sido suficiente y la teoría de la postcolonialidad será el comienzo de una verdadera liberación social e intelectual. Siempre ambas.

En esta etapa consideran una serie de acontecimientos históricos y teóricos que la marcaron como la "revolución nicaragüense, la divulgación de la teoría y la práctica de la Teología de la Liberación, conceptos como Cultura, democratización, global, pos(marxismo, modernismo, estructuralismo), las críticas de la desconstrucción, el feminismo; el reemplazo de los estudios multiculturales en los Estados Unidos, por una comprensión antropológica de la cultura como 'experiencia vivida' empieza a destacarse" (1997: 140) ${ }^{30}$.

Los miembros del GESLa critican de paso las antiguas concepciones cepalinas de los años 60 , y presentándose a sí mismos con un optimismo adánico no siempre justificado, señalan que "se empieza a percibir que las dinámicas culturales y políticas han empezado a funcionar en un contexto global que problematiza el modelo centro-periferia de la teoría de la dependencia y las estrategias del nacionalismo económico que parten de ese modelo" (1997: 141).

Es decir, además de la liberación política y metodológica, como lo intentaron los pensadores indios, se trata de un reordenamiento (crítico) de las ideas que precedieron a los Estudios Subalternos, para destacar su propia valorización; pues los autores de la "Declaración de fundación" se autoperciben como un amanecer con nuevas esperanzas políticas y académicas, y pasan de la descripción de las reflexiones de Guha a mencionar lo que denominan, "nuestro proyecto", aunque no presentan un programa coherente sino algunas intenciones generales, como la de recuperar, una vez más, el mundo del subalterno. Lo que dará origen más tarde al grupo Colonialidad/Modernidad ${ }^{31}$.

\footnotetext{
${ }^{30}$ Cursivas en el original.

${ }^{31}$ Rabasa entrega como antecedente del grupo Modernidad /Colonialidad que ha puesto el acento en la dominación epistemológica, el libro de Spivak, A Critique of Poscolonial Reason (1999), del que dice: "En este ensayo también ha resonado entre aquellos que estudian las formas mediante las cuales la historiografía colonial ejerce una violencia epistémica al constituir a las culturas indígenas bajo la rúbrica de superstición e idolatría [...]". Rabasa, José. "Poscolonialismo", op. cit. 222.
} 
Sin embargo, y a pesar del optimismo inicial creen que lograrlo es una misión casi imposible. Y esta dificultad se debe a su propia condición de intelectuales, pues por más que se esfuercen no logran alcanzar a ese sujeto popular. Por un lado una postura anti intelectual (desde lo intelectual) y por otra un sentido sacrificial: para poder llegar al subalterno, deben dejar de ser lo que son.

Nosotros necesitamos tener acceso al vasto (y móvil) arraigo de las masas -campesinos, proletarios, los sectores formales e informales, los sub y desempleados, vendedores, los que están fuera o al margen de la economía monetaria, lúmpenes y ex-lúmpenes de todas clases, niños, el creciente número de personas sin casa [...]. Nosotros necesitamos concluir esta declaración, sin embargo, con el reconocimiento de los límites de la idea de 'estudiar' lo subalterno y con una advertencia a nosotros mismos (1997: 144).

Como hemos dicho, se trata de una angustia muy antigua en América Latina: la de aquellos (sacerdotes, políticos, intelectuales) que intentaron hablar por los grupos marginales (indígenas, campesinos, obreros) y que fracasaron en el intento.

Una actitud antiintelectual que coincide, por ejemplo, con el comentario de Rigoberta Menchú citado en la última página de la "Declaración" como una conclusión final. Dice la Premio Nobel guatemalteca: "Sigo ocultando lo que yo considero que nadie lo sabe, ni siquiera un antropólogo, ni un intelectual, por más que tenga muchos libros, no saben distinguir nuestros secretos" (1997: 145) 32 .

Las sospechas señaladas hacia los intelectuales como sujetos comprometidos con el poder "establecido", tienen su origen en la obra póstuma de Ángel Rama, $L a$ ciudad letrada (1984), y más tarde por algunos de los propios pensadores indios, como Gayatri Spivak quien recoge las formulaciones de Foucault y Deleuze sobre sus desconfianzas en los intelectuales para mostrar la verdad de la realidad social ${ }^{33}$. Había dicho Foucault sobre este punto: "[...] los intelectuales han descubierto, después de las recientes luchas, que las masas no los necesitan para saber: ellas saben perfectamente, claramente, mucho mejor que ellos; y además lo dicen muy bien"34.

Es curioso que ante tanto optimismo inicial, el final de la "Declaración" sea el escepticismo ante la imposibilidad de alcanzar una propuesta real que

\footnotetext{
${ }^{32}$ Se refieren al texto de Rigoberta Menchú. Me llamo Rigoberta Menchú, y así me nació la conciencia. México: Siglo XXI, 1984.

${ }^{33}$ Comentarios a ese diálogo en Gayatri Chakravorty Spivak, “¿Puede hablar el sujeto subalterno?”, Orbis Tertius, 1998, III (6), 5.

34 "Un diálogo sobre el poder. Gilles Deleuze / Michel Foucault". El texto fue publicado inicialmente en la revista L'Arc, No 49, 1972. Y reproducido en el libro de Michel Foucault, Un diálogo sobre el poder y otras conversaciones, (Alianza Editorial). En: http://www.revistacontratiempo.com.ar/ foucault_deleuze.htm [Consultado: el 20 de marzo de 2012].
} 
pueda modificar las denunciadas injusticias del mundo latinoamericano y domina una relativización en el poder de las ideas y de aquellos que las practican profesionalmente, trasladando la antigua admiración por los intelectuales, propio de la cultura ilustrada occidental, a un sector popular que aunque iletrados son capaces de comprender e interpretar el mundo sin prejuicios ideológicos. Es decir, se trata de un esfuerzo (parcialmente imposible) por recuperar la realidad en desmedro de las acciones por parte de aquellos que sólo pueden interpretarla.

En este sentido se mantiene abierta la pregunta, ¿Qué se ha logrado de nuevo, en términos políticos en América Latina, después de la "Declaración de fundación del Grupo de Estudios Subalternos Latinoamericanos” de 1997?

\section{SIMILITUDES Y DIFERENCIAS: SUR/SOUTH}

He intentado establecer algunas semejanzas y diferencias entre los dos SUR, analizados desde los recientes pensadores de la postcolonialidad: el que representa al indio multirreligioso y al latinoamericano cristiano, al mestizo racial y al cultural, al dominado por el moderno imperio británico y por el tradicional imperio espańol; aunque ambos subalternos se igualen ante la mirada occidental por ser, ambos, representantes de la "otredad", a la misma distancia, pero de manera distinta del proyecto cartesiano.

Una de las más notorias diferencias es la disímil intención final de las propuestas intelectuales de unos y otros.

Chatterjee, por ejemplo, habla de los graves y reales problemas políticos de la postindependencia de su país. De los conflictos entre partidos y tendencias políticas, la separación de Pakistán (un grave error de la política colonial inglesa), del significado del concepto de ciudadanía, y sobre todo de la construcción de una sociedad democrática en un contexto cultural no democrático. En mi opinión, los estudios postcoloniales indios plantean desde su inicio una cuestión política de fondo: las críticas a la sociedad liberal, que no siempre es universalizable al resto del planeta. Escribe Chatterjee:

Argumentaré que la vieja idea, canonizada por la Revolución Francesa, de la soberanía popular y de un orden político y legal basado en la igualdad y en la libertad, ya no resulta adecuada para la organización de las demandas democráticas. En estos años vienen emergiendo nuevas formas de organización democrática, muchas veces contradictorias con los viejos principios de la sociedad civil liberal. Si bien se encuentran todavía de manera fragmentaria, incipiente e inestable, esta emergencia reclama de nuestra parte nuevas concepciones teóricas, que sean apropiadas para describir las formas de la política popular en la mayor parte del mundo (2008: 88). 
Por otro lado, y más allá de la paradoja anterior (democracia liberal sí, democracia liberal no), para Chatterjee la postmodernidad no afectó en India de modo tan radical como en Occidente en el sentido de dar por superado el proyecto moderno, pues este mantuvo vigencia en su país, tanto como el propio capitalismo. Chatterjee comprende la necesidad de mantener más allá de las especificidades de la India ciertas formas de la modernidad ineludibles para alcanzar el desarrollo económico y social.

¿Qué política moderna podría haber existido completamente al margen del capitalismo, de la maquinaria del Estado y de las matemáticas? [...]. En nuestros días no creo que resulte productivo tratar de restablecer este marco político utópico. O mejor dicho, no creo que ésta [la utopía] sea una opción disponible en el mundo postcolonial (2008: 85).

En cambio, en América Latina, las soluciones utópicas se han mantenido antes y después de la postcolonialidad, haciendo política a veces más cerca de los discursos culturales que desde la realidad social, muchas veces transformada en metáforas, como en el caso de los populismos de derecha e izquierda o en las oposiciones elitistas conservadoras a las necesarias reformas económicas y sociales del presente.

Pero al mismo tiempo Chatterjee nos asegura que lo que fracasó fue la Unión Soviética y no el comunismo dejando abierta la puerta para nuevas estructuras de organización social en los países del Tercer Mundo. Chatterjee, se esfuerza por encontrar soluciones reales en un mundo real y con un lenguaje real:

Parece que la historia ya hubiese decretado que nosotros, en el mundo postcolonial, deberíamos ser solamente unos consumidores perpetuos de la modernidad. Europa y América, los únicos sujetos verdaderos de la historia, habrían elaborado ya, en nuestro nombre, no sólo el guión de la Ilustración y la explotación colonial, sino también el de nuestra resistencia anticolonial. Y también el de nuestra miseria postcolonial. Incluso nuestras imaginaciones deben permanecer colonizadas para siempre (2008: 92).

\section{CRÍTICA A LOS CRÍTICOS}

Pero también han existido en América Latina una serie de pensadores críticos a la poscolonialidad, los que han relativizado la aplicación mecánica de las teorías de la subalternidad a su mundo y a su historia. ¿Qué ganamos con este nuevo concepto, se preguntan; a cuál reemplaza o cómo insertarlo en un horizonte intelectual descrito con anterioridad por categorías como civilización y barbarie, 
emancipación mental, positivismo criollo, indianismo, dependencia, centro periferia, nacionalismo defensivo?

Aceptarlo supone que tenemos rasgos comunes con los países de la periferia, una similar modernidad colonial, una cultura y economía marginal, los mismos problemas de atracción y rechazo con el centro, y un subdesarrollo económico equivalente. Supone también una reflexión sobre si los imperios actúan de igual forma en su imposición y dominio de los países colonizados. O si alguna vez concluye definitivamente la condición de colonialidad.

Entre los principales comentarios críticos se señala que la colonización en América Latina significó un mestizaje fecundo que se expresó no solo en el Barroco, como la expresión característica de la cultura colonial, y que produjo el surgimiento de autores cúspides de las letras como Huamán Poma de Ayala, Garcilaso de la Vega, Sigüenza y Góngora, F. Javier Clavijero, Sor Juana Inés, difíciles de encontrar en otras culturas y que desmiente el colonialismo tradicional afirmando el mestizaje creativo que no niega la subordinación, aunque la hace diferente.

Por otro lado, la época colonial latinoamericana ha sido muy estudiada y desde hace mucho tiempo con obras de gran profundidad en las que se han analizado su economía y organización social, su sincretismo cultural, con análisis que surgieron desde el inicio mismo de la Independencia. Autores como José Victorino Lastarria, Domingo F. Sarmiento ${ }^{35}$, Ricardo Palma, Miguel León Portilla, Mario Góngora, Gilberto Freire, Tulio Halperín Donghi, Pierre Villar, Octavio Paz, Lewis Hanke, Richard Konetzke, Bartolomé Bennassar, Pierre Chaunu, Joseph Pérez, y en los más recientes de James Lockhart, John Elliott y Eduardo Subirat, y tantos otros quienes han examinado aspectos generales y específicos de dicha época, con un gran número de estudios coloniales en muchos de los cuales se planteaban temas similares a los que más tarde pusieron sobre la mesa los postcolonialistas latinoamericanos.

Uno de estos autores, el historiador argentino Ricardo Levene, representa la tesis más extrema: América nunca fue una colonia completa, sino una continuidad jurídica y política de España: "[...] las Indias no eran colonias o factorías, sino provincias, reinos, seńoríos, repúblicas (esta última denominación en sentido etimológico); y de acuerdo a esa idea directriz se impone seguir el curso de sus fecundas consecuencias [...]” (1973: 10).

\footnotetext{
${ }^{35} \mathrm{La}$ modernización en las periferias posee un objetivo central, parecerse lo más posible al proyecto del centro mundial, pero con programas diversos. D.F. Sarmiento, por ejemplo, asume voluntariamente una neocolonización marcada por el idioma francés y la democracia burguesa para alcanzar la independencia definitiva: la espiritual y la material. Japón con Fukusawa intentó un proyecto similar, pero sin inmigrantes europeos y en su propio idioma. Y Mustafá Kemal Atatürk invitó a oficiales alemanes para que modernizaran su ejército y de paso la sociedad turca con una serie de medidas laicas y republicanas. En todo caso, en estas situaciones el subalterno estará ausente.
} 
No se trata de negar que en el llamado Nuevo Mundo no haya habido colonialismo ni que no haya funcionado el imperialismo espańol, sino que funcionó de otro modo, y más allá de lo exacto o no de las opiniones de Levene, nos interesa destacar la amplitud de estudios que han reflexionado en América sobre este tema y desde el inicio mismo de la aparición del mundo americano. Dice Levene, "esta potestad legislativa que España reconocía en todo tiempo a sus provincias ultramarinas, explica el proceso de formación autónoma política y jurídicamente de las nacionalidades del Nuevo Mundo" (1973: 33). Además, debemos mencionar a Jacques Lafaye ${ }^{36}$ y Robert Morse ${ }^{37}$, que han destacado a la sociedad latinoamericana como una cultura nueva, con aspectos de las anteriores que la constituyen pero distinta, más rica y variada a la hispánica y nativa que les dio origen.

Menciono estos autores solo para afirmar que el presente latinoamericano es algo más complejo que la condición de colonia de un imperio ya muy lejano en el tiempo, aunque en su interior mantenga niveles propios del colonialismo. La pertenencia a un imperio colonial es un buen argumento para justificar las desgracias del presente provocados por los propios errores de las administraciones locales.

Rolena Adorno, ha expresado dudas ante la afirmación que la teoría poscolonial pueda ser utilizada para un estudio de las situaciones coloniales en Hispanoamérica durante los siglos XVI y XVII, ya que aquellas ideas sólo son "aplicables únicamente al contexto mercantilista de las herencias coloniales británicas en los siglos XVIII y XIX, pero jamás a un mundo de la vida 'descapitalizado', por así decirlo, como era el de las herencias coloniales españolas antes del ascenso de los borbones" 38 .

Desde otro punto vista, Hernán Vidal afirma que el "discurso poscolonial" es producto de un "tecnocratismo académico" que se renueva por incitaciones de la novedad teórica en los centros intelectuales de poder (Foucault, Derrida, Lacan), desconectándose por completo de las "necesidades sociales" latinoamericanas.

Y habría que estudiar las diferencias entre el modelo hispánico y el británico de colonización que se ponen de manifiesto cuando Edward Said señala que los

${ }^{36}$ Ver: Lafaye, Jacques. Quetzalcóatl y Guadalupe. La formación de la conciencia nacional de México, 1531-1813. México: F. C. E, 1977. Les conquistadores, Seuil, Paris, 1964. "Literature and intellectual life in colonial Spanish America". En The Cambridge History of Latin America, Vol. II, Part IV. Cambridge: Cambridge University Press, (1984): 663-704.

${ }^{37}$ Ver: Morse, Robert. El espejo de Próspero. México: Siglo XXI, 1982. Resonancias del nuevo mundo. México: Vuelta, 1995.

${ }^{38}$ Ver: "Poscolonialismo", en Diccionario de Filosofía Latinoamericana, en http://www.cialc.unam. $\mathrm{mx} /$ pensamientoycultura/biblioteca\%20virtual/diccionario/poscolonialismo.htm [Consultado: el 15 de marzo de 2012]. 
ingleses siempre que se vieron obligados a abandonar una excolonia, la dividieron: "sucedió en la India, sucedió en Palestina, sucedió en Chipre, sucedió en Irlanda" (Said, 2002). En oposición a lo realizado por España, que intentó la unificación de las comunidades indígenas y criollas con la creación de entidades políticas que conservaran esta unidad ${ }^{39}$, por lo que habría que estudiar las razones del fracaso en la creación de los nuevos estados nacionales independientes.

Pero existen otras diferencias fundamentales, como que la inglesa era una monarquía con un proyecto "moderno" y la hispana con una visión de futuro antimoderna, barroca y religiosamente confesional. En este sentido, los indios ilustrados del siglo XIX que viajaron a Inglaterra, nos cuenta Chatterjee, observaron con admiración los conocimientos matemáticos, la arquitectura, los trenes y veleros, como símbolos de un poderoso imperio en ascenso ${ }^{40}$. En cambio, el criollo latinoamericano que viaja a la península en esa misma época, observa un imperio resquebrajado y en decadencia, del que le produce malestar descender y al que intenta reemplazar con un "galicismo mental": el intento de reemplazar voluntariamente un imperio por otro: el español por el francés o inglés ${ }^{41}$.

Sólo en América Latina, por otro lado, surgió un sujeto social que no es ni español ni indígena y que dará origen a una figura central (y vilipendiada): la del criollo, el cual, al tomar el poder durante la postindependencia, creará una nueva dominación de una manera diferente a la ibérica y a inglesa, estableciendo un poder que no es de castas ni de jerarquías señoriales, sino un dominio impuesto por la fuerza de los prejuicios sociales y una económica seudo capitalista.

En el mismo sentido, el teórico más conocido del "Grupo Latino Americano de Estudios Subalternos", el semiólogo argentino Walter Mignolo, y más tarde creador y portavoz del Grupo Modernidad /Colonialidad, piensa que el modelo indio de teorización poscolonial no debería ser utilizado para un análisis de situaciones coloniales en América Latina, pues corresponde a un "locus muy específico, anclado en las herencias coloniales británicas". Y agrega que lo que se debe preguntar es si, "análogamente a lo realizado por los poscoloniales indios, también en Latinoamérica existieron teorías capaces de subvertir las reglas del discurso colonial desde las herencias coloniales ibéricas.

\footnotetext{
${ }^{39}$ Fue esta situación particular lo que permitió la existencia de una Constitución política común para España y América en 1812. Un caso único, incluso desde antes de la independencia política plena.

${ }^{40}$ Hago referencia al capítulo "Quinientos años de amor y miedo", del libro de Partha Chatterjee. La nación en tiempo heterogéneo y otros estudios subalternos. Buenos Aires: Siglo XXI, 2008.

41 "Galicismo mental" fue la expresión con que Juan Valera caracterizó al modernismo literario. En relación a la actitud de Sarmiento, un galicista absoluto, véase mi trabajo, "España y América latina en 'Los Viajes' de D. F. Sarmiento. Una contribución al estudio del pensamiento liberal latinoamericano", en Libro-Homenaje a Leopoldo Zea. América latina. Historia y Destino. México: UNAM, 1992.
} 
En mi opinión han sido estas diferencias las que llevaron al surgimiento en ańos recientes de nuevas variantes de la poscolonialidad, aparecidas desde la propia realidad latinoamericana. Me refiero al Grupo Modernidad/Colonialidad, quienes propusieron desde la descolonización del "poder", del "saber" y del "ser" una forma de pensamiento, hoy en día, con mayor independencia de los indios y más centrados en la propia América Latina en general y su relación con el sistema y el pensamiento moderno.

\section{CONCLUSIONES. UNA SÍNTESIS Y UN BALANCE}

El GES de la India, contribuyó a replantear las antiguas discusiones sobre el mundo político y social de las excolonias con nuevas categorías y nuevos bríos que renovaron el ambiente intelectual del primer y del tercer mundo. Su principal mérito es haber contribuido a descentralizar la mirada y esbozar una identidad periférica de carácter mundial.

Las conceptualizaciones de esos estudios llegaron a América Latina y se relacionaron con el llamado "Pensamiento latinoamericano" que tenía una larga tradición de preguntas y respuestas sobre temas similares y en este contexto podemos visualizar a los Estudios Postcoloniales Latinoamericanos como un capítulo particular de aquella corriente, aunque se percibieron a sí mismos como una superación de todo pensamiento anterior pues pensaron que constituían un paradigma que cerraba los fracasos teóricos y políticos previos. Creyeron que la mirada postcolonial resolvía lo que había quedado pendiente en las anteriores metodologías. Frente a la postmodernidad, la desconstrucción, y el "fin de la historia" de Francis Fukuyama, esta nueva metodología correspondía exactamente a lo contrario, al inicio de originales interpretaciones históricas que permitían sospechar de todo concepto utilizado previamente y no sólo cuando se realizaran las futuras investigaciones sino también al analizar el pasado, pues ahora sí podríamos saber qué quiso decir exactamente Garcilaso de la Vega o Neruda cuando utilizan tal o cual visión de mundo o metáfora al instalar al subalterno como referente absoluto del sentido filosófico y político. Un nuevo punto de vista para mirar (también) hacia atrás, lo que Guha denomina como "writing in reverse". (Beverley, 1983: xiii).

La gran diferencia es que los pensadores indios, que venían del optimismo de la independencia reciente, junto a las propuestas epistemológicas de origen gramsciano, se propusieron mejorar la sociedad india y especialmente liberar a las amplias masas que habían vivido al margen de la sociedad colonial como de la independizada; mientras que a los latinoamericanos, que venían del escepticismo político de los años 70 , les interesó sobre todo crear nuevas conceptualizaciones teóricas. 
Es decir, el esfuerzo de los intelectuales indios en el inicio de los "Subaltern Studies", aunque también posee una intención académica ${ }^{42}$, es más comprometidamente político en sus reflexiones sobre el presente y el futuro de la India. En cambio, cuesta pensar que los esfuerzos del grupo latinoamericano puedan influir en el acontecer político del Continente, como sí han influido las reflexiones de los indios en cuestiones como el rol del nacionalismo, el socialismo y las clases sociales subalternas en la construcción de la nueva India, aunque no podemos negar las dificultades que algunos de ellos, como Spivak y Bhabha, tienen para vivir en la India, al ser considerados muy norteamericanizados. Con político quiero decir también estudios más empíricos, al menos, en sus comienzos ${ }^{43}$.

Los estudios subalternos en América Latina deben ser percibidos como una teoría entre otras teorías y en ocasiones en una metodología para resolver problemas de académicos que piensan desde libros para interpretar otros libros, constituyéndose en un capítulo de la Historia intelectual, más allá de la creencia de sus fundadores que pensaron que ahora sí, con esa metodología se podría resolver definitivamente los problemas sociales y políticos de América Latina.

\section{REFERENCIAS}

Barenboim, Daniel y Said, Edward W. Paralelismos y paradojas. Reflexiones sobre música y sociedad. Buenos Aires: Editorial Debate, 2002.

Beverley, John. Subalternity and Representation. Arguments in Cultural Theory. Durham and London: Duke University Press, 1999.

Bhabha, Homi K. Nación y narración. Entre la ilusión y una identidad y las diferencias culturales. Buenos Aires: Siglo XXI, 2010.

Bhabha, Homi K. El lugar de la cultura. Buenos Aires: Manantial, 2002.

\footnotetext{
${ }^{42}$ Piénsese en la creación de nuevos conceptos ("colonial knowledge", "análisis a contrapelo", Guha; "liminalidad”, Bhabha), o en la reelaboración de conceptos antiguos como: Subalterno, eurocentrismo, nacionalismo y sociedad postcolonial, Tercer Mundo.

${ }^{43}$ Este interés por lo político y particularmente por las luchas sociales campesinas, se observa en el libro de Guha. Elementary Aspects of Peasant Insurgency in Colonial India. New Delhi: Oxford University Press, 1983. O en el de A.R. Desai. Peasant Struggles in India, (1979), Agrarian Struggles in India After Independence, (1986). Citado por David Ludden, "A Brief History of Subalternity". En David Ludden (ed.), Subaltern Studies: Critical History, Contested Meaning, and the Globalisation of South Asia. New Delhi: Permanent Black, (2001): 5.
} 
Burkholder, Mark A. and Lyman L., Johnson. Colonial Latin America. New York Oxford: Oxford University Press, 1994.

Chakrabarty, Dipesh. El humanismo en la era de la globalización. La descolonización y las politicas culturales. Buenos Aires: Katz, 2009.

Chatterjee, Partha. La nación en tiempo heterogéneo y otros estudios subalternos. Buenos Aires: Siglo XXI, 2008.

"Declaración de Fundación del Grupo de Estudios Subalternos Latinoamericanos", Procesos. Revista Ecuatoriana de Historia, N¹0, I semestre, (1997): 135-147.

Diccionario de Filosofia Latinoamericana. Disponible en: http://www.cialc.unam.mx/ pensamientoycultura/biblioteca\%20virtual/diccionario/poscolonialismo. htm.

Dube, Saurabh, Ishita, Banarjee y Mignolo, Walter. Modernidades coloniales. México: El Colegio de México, 2004.

Dussel, Enrique. Filosofía de la liberación. México: Edicol, 1977.

Eisenstadt, Shmuel N. "Multiple Modernities", Daedalus, winter, (2000): 1-29.

Foucault, Michel. Un diálogo sobre el poder y otras conversaciones. Madrid: Alianza Editorial.Disponible en: http://www.revistacontratiempo.com.ar/foucault_ deleuze.htm.

Guha, Ranajit. Dominance Without Hegemony: History and Power in Colonial India. Cambridge: Harvard University Press, 1998.

Guha, Ranajit. Elementary Aspects of Peasant Insurgency in Colonial India. New Delhi: Oxford University Press, 1983.

Guha, Ranajit. "On some Aspects of the Historiography of Colonial India”. In Ranajit Guha (ed.), Subaltern Studies I. Writings on South Asian History and Society. New Delhi- Oxford Universitv Press, 1996 [1982]: 1-8. Traducción de Ana Rebeca Prada. Disponible en: http://www.ram-wan.net/restrepo/ contemp/guha-prefacio-1.pdf. 
Guha, Ranajit. "Preface". En Guha, Ranajit and Spivak, Gayatri (eds.), Selected Subaltern Studies. New York: Oxford University Press, 1988.

Levene, Ricardo. Las Indias no eran colonias. España: Espasa-Calpe, 1973.

Ludden, David (ed.), Subaltern Studies: Critical History, Contested Meaning, and the Globalization of South Asia. New Delhi: Permanent Black, 2001.

Mariátegui, José Carlos. 7 Ensayos de interpretación de la realidad peruana. Caracas: Biblioteca Ayacucho, 2007 [1928].

Mignolo, Walter. La idea de América. La herida colonial y la opción decolonial. Barcelona: Gedisa, 2005.

Pinedo, Javier. "El concepto Segunda Independencia en la historia de las ideas en América Latina: Una Mirada desde el Bicentenario", Revista Atenea, ${ }^{\circ}$ 502- II Semestre, (2010): 151-177.

Pinedo, Javier. "España y América Latina en 'Los Viajes' de D. F. Sarmiento. Una contribución al estudio del pensamiento liberal latinoamericano", en Libro-Homenaje a Leopoldo Zea, América latina. Historia y Destino. México: UNAM, (1992): 365-381.

Rama, Ángel. La ciudad letrada. Hanover: Ediciones del Norte, 1984.

Rodríguez, Simón. Sociedades Americanas. Caracas: Fundación Biblioteca Ayacucho, 1990 [1828].

Scannone, Juan Carlos. "La filosofía de la liberación: Historia, características, vigencia actual”, Teologia y Vida, Vol. L (2009): 59 -73.

Spivak, Gayatri Chakravorty 1998. “¿Puede hablar el sujeto subalterno?”, Orbis Tertius, III/6 (1998): 1-44.

Toro, Alfonso de. "La Postcolonialidad en Latinoamérica en la era de la globalización. ¿Cambio de paradigma en el pensamiento teórico-cultural latinoamericano?”. En Alfonso de Toro y Fernando de Toro (eds.), El debate de la postcolonialidad en Latinoamérica. Una postmodernidad periférica o Cambio de paradigma en el pensamiento latinoamericano. Frankfurt am Main: Vervuert, (1999): 31-77. 
Williams, Eric. Capitalism and Slavery. USA.: University of North Carolina Press, 1944.

Young, Robert J. C. Postcolonialism. An historical introduction. UK.: Blackwell Publishing, 2001.

Zea, Leopoldo. Discurso desde la marginación y la barbarie. Barcelona: Anthropos, 1988.

Zea, Leopoldo. "El pensamiento latinoamericano. Latinoamérica en busca de su identidad". Disponible en: http://www. Ensayistas.org/filosofos/mexico/ zea/pla/3-3.htm [Consultado: el 14 de abril de 2012]. 